\title{
Family Functioning, Emotional Intelligence, and Values: Analysis of the Relationship with Aggressive Behavior in Adolescents
}

\author{
María del Carmen Pérez-Fuentes ${ }^{1, *(D)}$, María del Mar Molero Jurado ${ }^{1}(\mathbb{D}$, \\ Ana Belén Barragán Martín ${ }^{1}$ and José Jesús Gázquez Linares ${ }^{1,2}$ \\ 1 Department of Psychology, University of Almería, 04120 Almería, Spain; mmj130@ual.es (M.d.M.M.J.); \\ abm410@ual.es (A.B.B.M.); jlinares@ual.es (J.J.G.L.) \\ 2 Department of Psychology, Universidad Autónoma de Chile, Región Metropolitana, \\ Providencia 7500000, Chile \\ * Correspondence: mpf421@ual.es; Tel.: +34-950-015-598
}

Received: 22 December 2018; Accepted: 2 February 2019; Published: 6 February 2019

\begin{abstract}
Aggressive behavior in adolescence is influenced by a diversity of individual, family, and social variables. The purpose of this study was to analyze the relationship between family functioning, emotional intelligence, and personal values for development with different types of aggression, as well as to establish profiles with these variables according to the aggression. The study was carried out with a sample of 317 high school students aged 13 to 18 years old. The study showed that stress management (emotional intelligence), positive adolescent development, and family functioning predominated in nonaggressive subjects with higher scores than aggressors did. There was also a negative relationship between the different types of aggression and emotional intelligence, positive values, and family functioning. In addition, two different profiles were found. The first profile had less family functioning, interpersonal emotional intelligence, stress management, and fewer personal and social values than the second profile.
\end{abstract}

Keywords: family functioning; aggressive behavior; emotional intelligence; adolescent values

\section{Introduction}

Violent behavior among secondary students has been identified as a serious problem in education today [1], with a corresponding increase in the number of studies on this topic in the literature [2,3]. Recent studies in several countries have shown that the prevalence of such adolescent behavior has increased [4,5], and poses a risk both for students who do not show this kind of behavior and educational activities in the school [6]. In view of the many problems in this context, the quality of coexistence in the school must be known before actions can be proposed or resources created [7].

\subsection{Violent Behavior in the School Environment}

Both physical and verbal aggressive behavior patterns may be found in the school, and these may be direct or indirect. For example, direct physical aggression refers to hitting someone while stealing would be an example of indirect physical aggression [8]. Direct verbal aggression refers to the insults between the actors involved in such situations, while talking about someone behind their back is considered indirect verbal aggression [9].

Aggression may also be classified by the method used to cause harm by differentiating between form and function [10]. The form of the aggression may be overt, which is manifested as physical and verbal aggressive behavior, such as threatening and hitting, or relational, which damages social inclusion within a group by social exclusion [11]. Function includes reactive aggression, which is 
characterized by behavior for revenge or getting even, while proactive aggression does not require provocation [12]. Both types of aggression have been studied in adolescent populations and in school-age children. Thus, the study by Manring, Elledge, Swails, \& Vernberg [13] in primary school showed reactive aggression as a longitudinal predictor of peer victimization, especially in girls. Similarly, individual factors are linked to relational aggression by girls, where it is an indicator of this type of problematic behavior [14]. There are also gender differences in the different types of aggression [15], where boys have higher percentages of reactive and proactive aggression than girls [16,17]. However, van Hazebroek, Olthof, and Goossens [18] found higher levels of reactive aggression in the group of boys than the group of girls, and no gender differences was found in proactive aggression.

Victim and aggressor profiles have different types of aggression. Jara, Casas, and Ortega-Ruiz [19] suggested that aggressors show proactive aggressive behavior, while reactive aggression is present in victims. Studies on relational violence have found different results concerning the sex of the aggressors. Ettekal and Ladd [20] showed that females participate more in relational violence. However, in other studies, no significant difference was found between men and women.

\subsection{Variables Related to Aggressive Behavior}

Adolescence is characterized by experimentation and sensation-seeking associated with impulsivity [21]. Aggression among youths is also linked to a series of individual, academic, family, and social factors [22]. Aggressive behaviors are related to personal and social values [23,24]. According to Jara et al. [19], social values are more important to aggressors than to victims, personal values are important to both agents, and individual values are stronger in aggressors than in victims. These authors also showed that there is a relationship between being a participant in aggressive behavior or not and social, personal, and individual values.

Likewise, there is a relationship between the different types of aggression and values for adolescent development, with a negative relationship between social and personal values and the different types of proactive and reactive aggression [25]. And in some studies, a positive relationship has been found between individualistic values and proactive aggression [26]. In turn, the family shows an impact on the internalization of the child's values, which are all supported by empirical evidence [27-30].

Aggressive behaviors are related to emotional, social, and other variables [31]. The study by Zych, Beltrán-Catalán, Ortega-Ruiz, and Llorent [32] showed that bullies had low levels of social and emotional competence, while their victims had the same levels as the students who were not involved. The family also plays an essential role in the emotional competence of the child [27,30,33,34]. Studies on emotional intelligence in victims and aggressors have demonstrated that students who are victims have low emotional intelligence. This means they have less ability to cope with stressful situations, and the aggressors show low levels of emotional intelligence as well, with low emotional regulation and deficient stress management [35]. At the same time, some authors state that poor emotional regulation is a characteristic of reactive aggression [17,36].

Regarding the variables of the family environment, even during adolescence, the family plays a key role in several different domains of adolescent competence and adaptation [33,37]. Aggressive behavior has been found to be related to family functioning [38]. Parents are a source of influence on youth functioning $[39,40]$ along with the group of peers, since conflictive settings, where conflict, criticism, insults, and lack of affection take precedence, may lead to aggressive behavior by not relating such behavior to its consequences [41]. According to studies done to date, parenting styles that employ physical and verbal aggression and hostile behavior are related to both the reactive and proactive functions of aggression. Thus, negative parenting and a dysfunctional environment are associated with proactive and reactive aggression [42].

In a recent study with Spanish adolescents [43], the family influence was analyzed in adolescents' aggressive behaviors, antisocial behavior, school adjustment, and self-esteem. They were able to verify 
that the family was not only a protective factor against aggressive behaviors, but benefitted school adjustment and self-esteem. These, in turn, acted as protectors against antisocial behavior.

The review of the literature showed the relationship between types of aggression and variables such as emotional intelligence, values, and family functioning to be negative [44], personal and social values diminished [45], and a higher risk of family dysfunction [46].

At the present time, there are few studies profiling subjects by type of aggression [47], or the relationship of these types and emotional intelligence, family functioning, and values.

\subsection{The Study}

The objective of this study was to analyze the relationship between emotional intelligence, development values, family functioning, and the various types of aggressive behavior. At the same time, we wanted to form profiles by aggression predictor variables for the different types of aggression.

In view of previous studies, the following specific hypotheses were posed: (1) student aggressors score higher on all types of aggression than non-aggressors, (2) emotional intelligence, values, and family functioning are predictor variables of the appearance of aggressive behavior in the study sample.

\section{Materials and Methods}

\subsection{Participants}

A cross-sectional study was done with random cluster sampling. The sample consisted of a total of 317 students aged 13 to 18 years old $(M=14.93, S D=1.06)$ at two high schools in the province of Almeria (Spain). The group of boys made up $50.8 \%(n=161)$ with a mean age of $14.85(S D=1.00)$ and girls $49.2 \%(n=156)$ with a mean age of $15.01(S D=1.11)$. The sample was distributed over two grades, $61.5 \%(n=195)$ in the third year of high school and $38.5 \%(n=122)$ in the fourth year.

\subsection{Instruments}

An ad hoc questionnaire for sociodemographic data (age, sex, grade) and questions on student involvement in peer violence at school ("Have you ever experienced episodes of violence by other students?" "Have you ever used violence against the other students?" "Have you ever seen violence against other students?" "Did you intervene when you saw someone using violence against other students?").

Adolescent aggression was assessed with the Peer Conflict Scale (PCS) [48]. The Spanish adaptation from Pérez-Fuentes et al. [49] was used. This scale evaluates the overt and relational forms and reactive and proactive functions of aggression. It consists of 40 items, with answers rated on a four-point Likert-type scale (where 0 is not at all true and 3 is definitely true). In this study, the reliability for each scale was 0.81 for overt proactive aggression (item sample, "I start fights to get what I want"), 0.85 for overt reactive aggression (item sample, "When someone hurts me, I just get into a fight"), 0.81 for Relational proactive aggression (item sample, "I like to make fun of others"), and 0.78 for Reactive relational aggression (item sample, "I spread rumors and lies about others when they do something bad to me"), and, for the overall scale, reliability was $\alpha=0.92$.

Family Functioning was evaluated with the Family Functioning Scale (APGAR) [50]. The Spanish adaptation of the original version [51] was used. This scale consists of five items, which evaluate Adaptability, Growth, Partnership, Affection and Resolve ("Are important decisions taken together at home?"), with three answer choices ( $0=$ hardly ever, $1=$ some of the time and $2=$ almost always). There are also three function categories, highly dysfunctional (0 to 3), moderately dysfunctional (4 to 6), and functional ( 6 or more). In this study, the Cronbach's alpha was of 0.75 . Regarding the validity of the scale, it has been discussed by authors such as Gardner et al. [52].

Emotional Intelligence was evaluated with the Brief Emotional Intelligence Inventory for Senior Citizens (EQ-I-M20) [53]. The adaptation by Pérez-Fuentes, Gázquez, Mercader, and y Molero [54] was validated and scaled in an adult Spanish population. This inventory is comprised of 20 items, which are distributed in five factors including Intrapersonal (It's easy for me to tell people how I feel), Interpersonal ("I know how other people feel"), Stress Management ("I find it hard to control my rage"), Adaptability ("I can solve problems in different ways"), and Mood ("I feel sure of myself"), 
which was answered on a four-point Likert-type scale. For this sample, the instrument's internal consistency was 0.78 , and, for each of the subscales, reliability was Intrapersonal $\alpha=0.77$, Interpersonal $\alpha=0.67$, Stress Management $\alpha=0.76$, Adaptability $\alpha=0.46$, and Mood $\alpha=0.83$.

Values for Positive Adolescent Development were evaluated with the Scale of Values for Positive Adolescent Development (EV-DPA) [55]. This consists of 24 items, which evaluate the importance that values are given by youths for their positive development. The answers are rated on a scale from 1 to 7 , where 1 is "not important at all" and 7 is "the most important." The scale is comprised of three dimensions: Social values (Defend the rights of others), Personal values (Be honest with others), and Individualist values (Receive praise from other persons), which had the following reliability: Social values $\alpha=0.88$, Personal values $\alpha=0.83$, and Individualist values $\alpha=0.79$, and the overall scale had a Cronbach's alpha of 0.91 .

\subsection{Procedure}

First, the high school principals were contacted to inform them of the objectives, methods, and use of data, and also receive their consent. The pertinent permissions were requested on an informed consent sheet addressed to the parents/guardians, and, before the tests were implemented, only students who had paternal authorization were permitted to participate. Second, the students were told that participation was voluntary and given the necessary instructions to fill out the questionnaire. They were also informed of the confidentiality and anonymity of data management. The study was approved by the Bioethics Committee of the University of Almería.

\subsection{Data Analyses}

The SSPS version 23.0 for Windows (SPSS Inc., Chicago, IL, USA) was used for data processing and analysis.

First, the descriptive analysis was done, and, in order to explore the relationships between variables, bivariate correlations were analyzed. Then, a stepwise multiple linear regression analysis was carried out with the aggression forms (overt proactive aggression, overt reactive aggression, relational proactive aggression, and relational reactive aggression) as the dependent variables. The predictor variables were emotional intelligence, values for positive adolescent development, and family functioning. Specifically, the variables that were correlated to the dependent variable were used to estimate the regression model in each case.

Lastly, a two-step cluster analysis was done to determine the profiles, using the variables that were included in each of the regression models. After the groups were classified based on the cluster solution, the means were compared using the Student's $t$ for independent samples to find out whether there were any differences between clusters with respect to types of aggression, and the Cohen's $d$ test was used to determine the effect size.

\section{Results}

\subsection{Aggressive Conducts in Secondary Compulsory Education Students: Descriptive Analysis}

Of the total sample, $13.6 \%(n=43)$ had experienced or were currently suffering from violence by other students. On the contrary, $12.9 \%(n=41)$ had used or were using some type of violence on other students, and $65.3 \%(n=207)$ had seen violence used on other students.

The gender distribution of the aggressors was $78 \%(n=32)$ boys and $22 \%(n=9)$ girls. In the group of victims, $55.8 \%(n=24)$ were boys and $44.2 \%(n=19)$ were girls.

The mean scores in the total sample for each of the dimensions of aggression were the following: overt proactive aggression $(M=0.24 ; S D=0.37)$, overt reactive aggression $(M=0.55 ; S D=0.54)$, relational proactive aggression $(M=0.22 ; S D=0.35)$, and relational reactive aggression $(M=0.30$; $S D=0.37)$. There were significant differences in over proactive aggression by $\operatorname{sex}\left(t_{(315)}=3.36, p<0.01\right.$, $d=0.38)$, where boys had higher scores $(M=0.30, S D=0.43)$ than girls $(M=0.16, S D=0.28)$. In relational proactive aggression, boys $(M=0.27, S D=0.41)$ had significantly higher scores $\left(t_{(315)}=2.38, p<0.05\right.$, $d=0.27)$ than girls $(M=0.18, S D=0.28)$. 
In the group of aggressors, mean scores were significantly higher for all types of aggression (overt proactive aggression $\left(t_{(315)}=3.66, p<0.01, d=0.61\right)$, overt reactive aggression $\left(t_{(315)}=4.58, p<0.001\right.$, $d=0.77)$, relational proactive aggression $\left(t_{(315)}=3.39, p<0.01, d=0.57\right)$, and Relational reactive aggression $\left.\left(t_{(315)}=2.40, p<0.05, d=0.40\right)\right)$, compared to the group of nonaggressors. The group of victims had a significantly higher mean in overt reactive aggression $\left(t_{(315)}=1.99, p<0.05, d=0.33\right)$, than the group of nonvictims.

The age of participants was not correlated with any of the types of aggression analyzed.

\subsection{Emotional Intelligence, Values, and Family Functioning: Relationship with Aggression}

The results derived from the correlation analysis, as shown in Table 1, indicate that Overt proactive aggression correlated negatively with most of the emotional intelligence factors (Intrapersonal: $r=-0.13, p<0.05$, Interpersonal: $r=-0.18, p<0.01$, Stress management: $r=-0.20, p<0.001$, Mood: $r=-0.15 ; p<0.01)$, with Social values $(r=-0.26, p<0.001)$, Personal values $(r=-0.26$, $p<0.001)$, and Family functioning $(r=-0.20, p<0.001)$. Overt reactive aggression had negative correlations with stress management $(r=-0.41, p<0.001)$, Social values $(r=-0.17, p<0.01)$, Personal values $(r=-0.15, p<0.01)$, and Family functioning $(r=-0.17, p<0.01)$.

In relational proactive aggression, negative correlations were observed with some of the dimensions of emotional intelligence (Intrapersonal: $r=-0.13, p<0.05$, interpersonal: $r=-0.20$, $p<0.001$, stress management: $r=-0.17, p<0.01)$, social values $(r=-0.24, p<0.001)$, personal values $(r=-0.24, p<0.001)$, and family functioning $(r=-0.18, p<0.01)$.

Lastly, relational reactive aggression is negatively correlated with stress management $(r=-0.22$, $p<0.001)$, $\operatorname{mood}(r=-0.12, p<0.05)$, social values $(r=-0.12, p<0.05)$, personal values $(r=-0.17$, $p<0.01)$, and family functioning $(r=-0.12, p<0.05)$. In general, the values of the correlations are between 0.2 to 0.4 , which indicates a degree of statistical dependence among the weak variables.

Based on the results found in the correlation analyses, multiple regression models were constructed for each of the types of aggression, considering the variables in which correlations were detected in each case and entering them in the model as possible predictors.

\subsection{Multiple Regression Model: Overt Proactive Aggression}

As shown by the data presented in Table 2, the regression analysis found three models, where the third is the one with the most explanatory capacity, with $12.7 \%\left(R^{2}=0.12\right)$ of the variance explained by the factors included in the model.

Independence of residuals was analyzed to confirm the validity of the model. The Durbin-Watson was $D=1.90$, which confirms the absence of positive or negative self-correlation. The $t$ is associated with a probability of error below 0.05 in all the variables included in the model (social values, stress management, and family functioning), while the standardized coefficients reveal that the variable with the most explanatory weight is social values. Lastly, absence of collinearity between the variables included in the model may be confirmed by the high tolerance and low VIF.

\subsection{Multiple Regression Model: Overt Reactive Aggression}

Table 3 shows the regression analysis for the three models in which the last explains $21.7 \%$ of the variance $\left(R^{2}=0.21\right)$. The Durbin-Watson $D(D=1.55)$ confirmed the absence of positive or negative self-correlation.

The $t$ was associated with a probability of error below 0.05 for all the variables included in the model, and the standardized coefficients reveal that the variable with the most explanatory weight is stress management. Absence of collinearity may be assumed with tolerance and VIF near one.

\subsection{Multiple Regression Model: Relational Proactive Aggression}

The regression analysis of Relational proactive aggression, as shown in Table 4, resulted in four models, of which the fourth model had the most explanatory capacity with $12.2 \%\left(R^{2}=0.12\right)$ of the variance explained by the factors included in the model. 
Table 1. Correlations between types of aggression and emotional intelligence variables, values, and family functioning.

\begin{tabular}{|c|c|c|c|c|c|c|c|c|c|c|c|c|}
\hline Variables & 1 & 2 & 3 & 4 & 5 & 6 & 7 & 8 & 9 & 10 & 11 & 12 \\
\hline 1. Overt proactive aggression & - & & & & & & & & & & & \\
\hline 2. Overt reactive aggression & $0.61 * * *$ & - & & & & & & & & & & \\
\hline 3. Relational proactive aggression & $0.79^{* * *}$ & $0.50^{* * *}$ & - & & & & & & & & & \\
\hline 4. Relational reactive aggression & $0.76^{* * *}$ & $0.58^{* * *}$ & $0.79^{* * *}$ & - & & & & & & & & \\
\hline 5. Intrapersonal & $-0.13^{*}$ & -0.04 & $-0.13 *$ & -0.08 & - & & & & & & & \\
\hline 6. Interpersonal & $-0.18^{* *}$ & 0.19 & $-0.20^{* * *}$ & -0.07 & $0.28^{* * *}$ & - & & & & & & \\
\hline 7. Stress management & $-0.20^{* * *}$ & $-0.41^{* * *}$ & $-0.17 * *$ & $-0.22 * * *$ & -0.00 & -0.10 & - & & & & & \\
\hline 8. Adaptability & -0.01 & 0.02 & -0.05 & -0.02 & $0.14^{* *}$ & $0.36^{* * * *}$ & -0.09 & - & & & & \\
\hline 9. Mood & -0.15 ** & -0.10 & -0.08 & -0.12 * & $0.31^{* * *}$ & $0.19^{* * *}$ & 0.03 & $0.22 * * *$ & - & & & \\
\hline 10. Social values & $-0.26^{* * *}$ & $-0.17^{* *}$ & $-0.24^{* * *}$ & $-0.12 *$ & $0.17^{* *}$ & $0.40^{* * *}$ & 0.05 & $0.23^{* * *}$ & $0.11 *$ & - & & \\
\hline 11. Personal values & $-0.26^{* * *}$ & $-0.15^{* *}$ & $-0.24^{* * *}$ & $-0.17^{* *}$ & $0.18^{* *}$ & $0.39 * * *$ & -0.00 & $0.27^{* * *}$ & 0.06 & $0.74^{* * *}$ & - & \\
\hline 12. Individualist values & 0.02 & 0.08 & 0.02 & 0.09 & $0.15^{* *}$ & $0.18^{* *}$ & $-0.17^{* *}$ & $0.15^{* *}$ & $0.14^{* *}$ & $0.40^{* * *}$ & $0.47^{* * *}$ & - \\
\hline 13. Family functioning & $-0.20^{* * *}$ & $-0.17^{* *}$ & $-0.18^{* *}$ & $-0.12 *$ & $0.19^{* * *}$ & $0.13^{*}$ & 0.03 & 0.09 & $0.30^{* * *}$ & $0.20^{* * *}$ & $0.19^{* * *}$ & $0.18^{* *}$ \\
\hline
\end{tabular}

Table 2. Stepwise Multiple Linear Regression Model (overt proactive aggression).

\begin{tabular}{|c|c|c|c|c|c|c|c|c|c|}
\hline \multirow{2}{*}{ Model } & \multirow{2}{*}{$R$} & \multirow{2}{*}{$R^{2}$} & \multirow{2}{*}{$\begin{array}{c}R^{2} \\
\text { Adjusted }\end{array}$} & \multicolumn{5}{|c|}{ Change Statistics } & \multirow{2}{*}{$\begin{array}{l}\text { Durbin } \\
\text { Watson }\end{array}$} \\
\hline & & & & SE & Change in $R^{2}$ & Change in $F$ & Significanc & lange in $F$ & \\
\hline 1 & 0.26 & 0.07 & 0.06 & 0.36 & 0.07 & 23.54 & \multicolumn{2}{|c|}{0.000} & \multirow{3}{*}{1.90} \\
\hline 2 & 0.32 & 0.10 & 0.10 & 0.35 & 0.03 & 12.70 & \multicolumn{2}{|c|}{0.000} & \\
\hline \multirow[t]{3}{*}{3} & 0.35 & 0.12 & 0.11 & 0.35 & 0.02 & 7.72 & \multicolumn{2}{|c|}{0.006} & \\
\hline & \multirow{2}{*}{\multicolumn{2}{|c|}{ Model 3}} & \multicolumn{2}{|c|}{ Unstandardized Coefficients } & $\begin{array}{c}\text { Standardized } \\
\text { Coefficients }\end{array}$ & \multirow[t]{2}{*}{$t$} & \multirow[t]{2}{*}{ Sig. } & \multicolumn{2}{|c|}{ Collinearity } \\
\hline & & & $B$ & SE & Beta & & & Tol. & VIF \\
\hline (Constant) & & & 0.98 & 0.11 & & 8.74 & 0.000 & & \\
\hline Social value & & & -0.07 & 0.01 & -0.22 & -4.13 & 0.000 & 0.95 & 1.04 \\
\hline Stress mana & & & -0.08 & 0.02 & -0.18 & -3.53 & 0.000 & 0.99 & 1.00 \\
\hline Family func & & & -0.02 & 0.00 & -0.15 & -2.77 & 0.006 & 0.95 & 1.04 \\
\hline
\end{tabular}


Table 3. Stepwise Multiple Linear Regression Model (overt reactive aggression).

\begin{tabular}{|c|c|c|c|c|c|c|c|c|c|}
\hline \multirow{2}{*}{ Model } & \multirow{2}{*}{$R$} & \multirow{2}{*}{$R^{2}$} & \multirow{2}{*}{$R^{2}$ Adjusted } & \multicolumn{5}{|c|}{ Change Statistics } & \multirow{2}{*}{$\begin{array}{l}\text { Durbin } \\
\text { Watson }\end{array}$} \\
\hline & & & & SE & Change in $R^{2}$ & Change in $F$ & \multicolumn{2}{|c|}{ Sig. F Change } & \\
\hline 1 & 0.41 & 0.17 & 0.17 & 0.49 & 0.17 & 66.81 & \multicolumn{2}{|c|}{0.000} & \\
\hline 2 & 0.44 & 0.20 & 0.19 & 0.49 & 0.02 & 9.83 & \multicolumn{2}{|c|}{0.002} & 1.55 \\
\hline 3 & 0.46 & 0.21 & 0.20 & 0.48 & 0.01 & 6.72 & \multicolumn{2}{|c|}{0.010} & \\
\hline \multirow{2}{*}{\multicolumn{3}{|c|}{ Model 3}} & \multicolumn{2}{|c|}{ Unstandardized Coefficients } & Standardized Coefficients & \multirow{2}{*}{$t$} & \multirow{2}{*}{ Sig. } & \multicolumn{2}{|c|}{ Collinearity } \\
\hline & & & $B$ & SE & Beta & & & Tol. & VIF \\
\hline (Constant) & & & 1.85 & 0.17 & & 10.37 & 0.000 & & \\
\hline Stress man & ment & & -0.26 & 0.03 & -0.41 & -8.28 & 0.000 & 0.99 & 1.00 \\
\hline Family fun & ning & & -0.03 & 0.01 & -0.13 & -2.59 & 0.010 & 0.96 & 1.04 \\
\hline Personal va & & & -0.07 & 0.02 & -0.13 & -2.59 & 0.010 & 0.96 & 1.04 \\
\hline
\end{tabular}

Table 4. Stepwise Multiple Linear Regression Model (relational proactive aggression).

\begin{tabular}{|c|c|c|c|c|c|c|c|c|c|}
\hline \multirow{2}{*}{ Model } & \multirow{2}{*}{$R$} & \multirow{2}{*}{$R^{2}$} & \multirow{2}{*}{$R^{2}$ Corrected } & \multicolumn{5}{|c|}{ Change Statistics } & \multirow{2}{*}{$\begin{array}{l}\text { Durbin } \\
\text { Watson }\end{array}$} \\
\hline & & & & SE & Change in $R^{2}$ & Change in $F$ & \multicolumn{2}{|c|}{ Sig. F Change } & \\
\hline 1 & 0.24 & 0.06 & 0.05 & 0.34 & 0.06 & 20.28 & \multicolumn{2}{|c|}{0.000} & \\
\hline 2 & 0.29 & 0.08 & 0.08 & 0.34 & 0.02 & 9.44 & \multicolumn{2}{|c|}{0.002} & 1.96 \\
\hline 3 & 0.32 & 0.10 & 0.09 & 0.34 & 0.01 & 6.72 & \multicolumn{2}{|c|}{0.010} & \\
\hline 4 & 0.34 & 0.12 & 0.11 & 0.33 & 0.01 & 5.23 & \multicolumn{2}{|c|}{0.023} & \\
\hline \multirow{2}{*}{\multicolumn{3}{|c|}{ Model 4}} & \multicolumn{2}{|c|}{ Unstandardized Coefficients } & Standardized Coefficients & \multirow{2}{*}{$t$} & \multirow{2}{*}{ Sig. } & \multicolumn{2}{|c|}{ Collinearity } \\
\hline & & & $B$ & SE & Beta & & & Tol. & VIF \\
\hline (Constant & & & 1.04 & 0.12 & & 8.08 & 0.000 & & \\
\hline Social Val & & & -0.04 & 0.01 & -0.15 & -2.58 & 0.010 & 0.80 & 1.24 \\
\hline Stress ma & nent & & -0.07 & 0.02 & -0.18 & -3.37 & 0.001 & 0.97 & 1.02 \\
\hline Interpers & & & -0.08 & 0.03 & -0.14 & -2.46 & 0.014 & 0.81 & 1.22 \\
\hline Family fu & ing & & -0.01 & 0.00 & -0.12 & -2.28 & 0.023 & 0.95 & 1.04 \\
\hline
\end{tabular}


To confirm model validity, independence of residuals was analyzed. The Durbin-Watson $D$ was $D=1.96$, which confirms the absence of positive or negative self-correlation. It was further observed that the $t$ was associated with a probability of error below 0.05 in all the variables included in the model. In addition, the standardized coefficients revealed that the variables with the most explanatory weight were stress management and social values. Lastly, since tolerance was high and VIF was low, the absence of collinearity between variables may be assumed.

\subsection{Multiple Regression Model: Relational Reactive Aggression}

Table 5 shows the two models resulting from the regression analysis, of which the second model has an explained variance of $8.1 \%\left(R^{2}=0.08\right)$. In this case, the Durbin-Watson $D$ confirmed model validity $(D=1.91)$. The $t$ test detected association with a probability of error below 0.05 for the variables included in the model: stress management and personal values. According to the standardized coefficients, stress management was the strongest predictor of relational reactive aggression. The $t$ test showed an association with a probability of error less than 0.05 for the variables included in the model, stress management, and personal values. According to the standardized coefficients, stress management is the strongest predictor of Relational reactive aggression. In view of the tolerance and VIF, the absence of collinearity between variables may be assumed.

Table 5. Stepwise Multiple Linear Regression Model (relational reactive aggression).

\begin{tabular}{|c|c|c|c|c|c|c|c|c|c|}
\hline \multirow[t]{2}{*}{ Model } & \multirow[t]{2}{*}{$R$} & \multirow[t]{2}{*}{$R^{2}$} & \multirow{2}{*}{$\begin{array}{c}R^{2} \\
\text { Adjusted }\end{array}$} & \multicolumn{5}{|c|}{ Change Statistics } & \multirow[t]{2}{*}{$\begin{array}{l}\text { Durbin } \\
\text { Watson }\end{array}$} \\
\hline & & & & SE & Cambio en $R^{2}$ & Cambio en $F$ & \multicolumn{2}{|c|}{ Sig. F Change } & \\
\hline 1 & 0.22 & 0.05 & 0.04 & 0.36 & 0.05 & 16.40 & \multicolumn{2}{|c|}{0.000} & \multirow{2}{*}{1.91} \\
\hline 2 & 0.28 & 0.08 & 0.07 & 0.36 & 0.03 & 10.69 & \multicolumn{2}{|c|}{0.001} & \\
\hline \multirow{2}{*}{\multicolumn{3}{|c|}{ Model 2}} & \multicolumn{2}{|c|}{$\begin{array}{l}\text { Unstandardized } \\
\text { Coefficients }\end{array}$} & $\begin{array}{l}\text { Standardized } \\
\text { Coefficients }\end{array}$ & $t$ & Sig. & \multicolumn{2}{|c|}{ Collinearity } \\
\hline & & & $B$ & SE & Beta & & & Tol. & VIF \\
\hline \multicolumn{3}{|c|}{ (Constant) } & 0.90 & 0.12 & & 7.23 & 0.000 & & \\
\hline \multicolumn{3}{|c|}{ Stress management } & -0.09 & 0.02 & -0.22 & -4.13 & 0.000 & 1.00 & 1.00 \\
\hline \multicolumn{3}{|c|}{ Personal values } & -0.06 & 0.02 & -0.17 & -3.27 & 0.001 & 1.00 & 1.00 \\
\hline
\end{tabular}

\subsection{Profiles According to Predictor Variables of Aggression and the Different Types of Aggression}

A two-step cluster analysis was done with the variables that were included in the multiple linear regression models described above (family functioning, social values, personal values, stress management, and the interpersonal factor). For cluster construction, family functioning was taken as the categorical variable such that 0 to 3 points meant dysfunctional, 4 to 6 meant moderately functional, and 7 to 10 points was considered functional. In this case, family functioning is the predictor with the most relevance in cluster construction (Figure 1).

The inclusion of these variables resulted in two groups (Figure 1), with the following distribution: $30.6 \%(n=97)$ of the participants in Cluster 1 and $69.4 \%(n=220)$ in Cluster 2. Table 6 summarizes the mean scores on the variables analyzed in the total sample and for each of the clusters.

The first group resulting from the cluster analysis (Cluster 1) was characterized by low-moderate family functioning, mean scores below those found for the total sample in personal and social values, and similar to the sample mean interpersonal factor and stress management. While in the second cluster, with high family functioning, the mean scores were higher than the whole sample for personal and social values with scores near the sample mean in interpersonal and stress management. 
After the groups were classified, based on the two-cluster solution, a Student's $t$ test for independent samples was done to find out whether there were any differences between clusters by type of aggression. The significant differences between the clusters were in Overt proactive aggression $\left(t_{(315)}=2.22, p<0.05, d=0.27\right)$, where Cluster $1(M=0.31, D T=0.44)$ had higher scores than Cluster $2(M=0.20, D T=0.33)$. No significant differences were observed for the rest of the types of aggression.

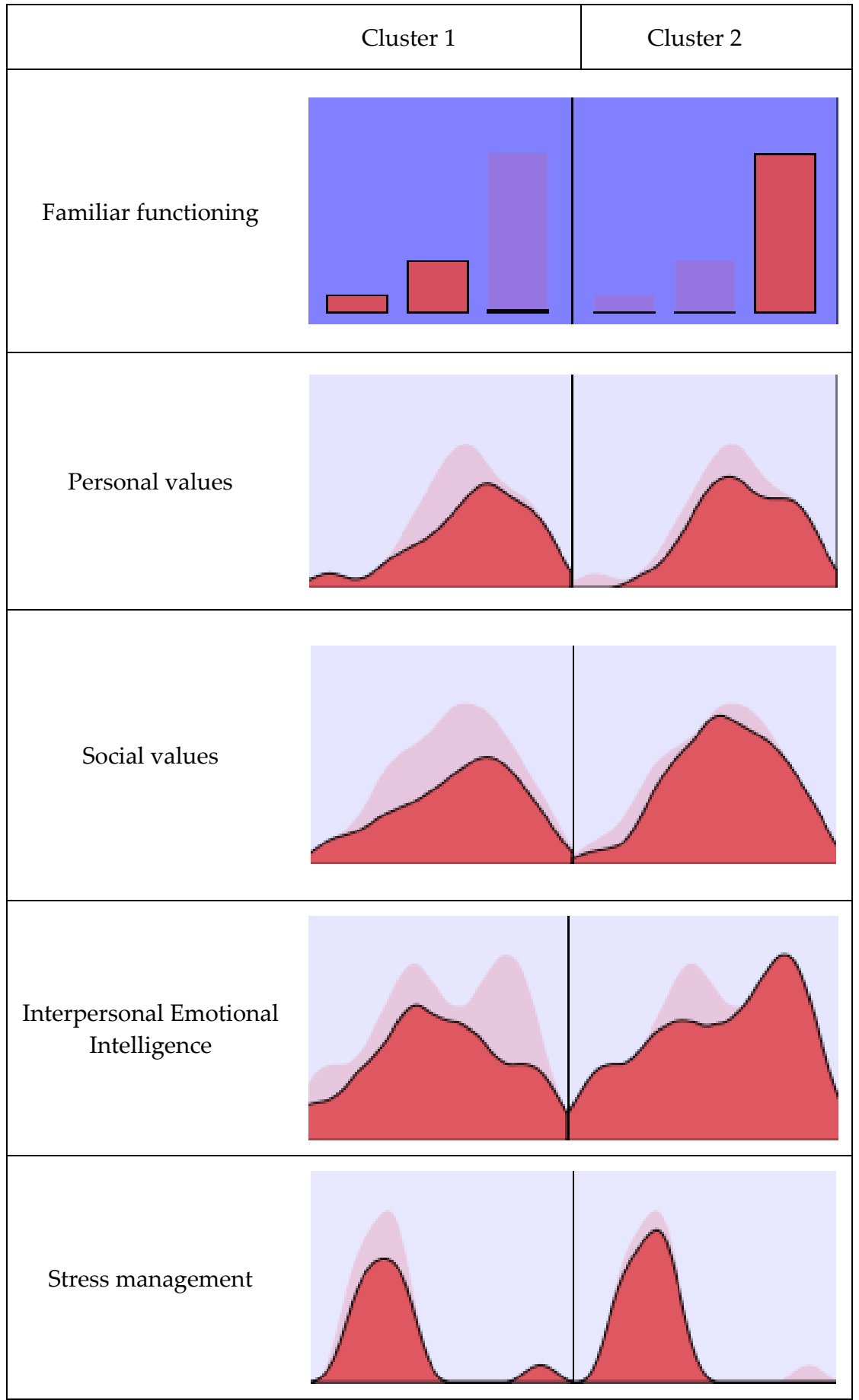

Figure 1. Cluster composition. Note: factors in order of importance of input. 
Table 6. Mean scores for the total sample and clusters.

\begin{tabular}{|c|c|c|c|}
\hline \multirow[b]{2}{*}{ Variables } & \multirow[b]{2}{*}{ Total Sample $(N=317)$} & \multicolumn{2}{|c|}{ Cluster } \\
\hline & & $\begin{array}{c}1 \\
(n=97)\end{array}$ & $\begin{array}{c}2 \\
(n=220)\end{array}$ \\
\hline Family functioning & $M=7.44(D T=2.32)$ & $M=4.51(D T=1.65)$ & $M=8.73(D T=1.05)$ \\
\hline Personal values & $M=5.38(D T=1.02)$ & $M=5.15(D T=1.15)$ & $M=5.48(D T=0.94)$ \\
\hline Social values & $M=4.89(D T=1.16)$ & $M=4.67(D T=1.26)$ & $M=4.98(D T=1.11)$ \\
\hline $\begin{array}{l}\text { Interpersonal Emotional } \\
\text { Intelligence }\end{array}$ & $M=2.94(D T=0.59)$ & $M=2.89(D T=0.63)$ & $M=2.97(D T=0.58)$ \\
\hline Stress management & $M=2.59(D T=0.85)$ & $M=2.63(D T=1.01)$ & $M=2.57(D T=0.78)$ \\
\hline
\end{tabular}

\section{Discussion}

Aggressive behavior is present in adolescence and its prevalence in recent years has been increasing $[1,3]$. The results of this study showed the percentages of students who have experienced or experience violence by their peers and those who have used violence on other students. Although these percentages are not too high, they are in consonance with those of Crespo-Ramos et al. [4] and may be due to the differences in the sample size. With regard to the sex of the aggressor, the percentage of boys is significantly higher than girls, which coincides with other studies where the highest percentages are for males [16,17]. On the contrary, in the study by Manring et al. [13] performed in primary school, the girls had higher scores. Nevertheless, in the group of victims, there were no significant differences between sexes.

The differences in scores by sex in the different types of aggression were only significant in Overt proactive aggression and Relational proactive aggression, where boys scored higher than girls in both. These results are in agreement with those found by Rieffe et al. [17] where boys had high percentages in both proactive and reactive aggression, but not with Van Hazebroek et al. [18] who found that it was reactive aggression where boys predominated, and no sex differences were found in proactive aggression. The results for the characterization of victim and aggressor, according to each of the aggression scales, showed that the group of aggressors had significantly higher means on all the scales than the nonaggressors. This coincides with other studies where the aggressors had Proactive aggressive behavior $[19,20]$, while victims had higher scores in overt reactive aggression.

With regard to the correlation between the types of aggression and the emotional intelligence, values, and family functioning variables, we found a negative relationship, since, at higher levels of aggressiveness, emotional intelligence levels are lower [36,44], personal and social values are lower, and there is a higher risk of family dysfunction [42,46].

The multiple regression analysis showed that overt and relational proactive aggression were predicted or explained based on social values, stress management, and family functioning, including the interpersonal dimension in relational proactive aggression. In both overt and relational reactive aggression, the stress management and personal value dimensions stood out. Furthermore, family functioning was included in the first type. These results are in line with other studies where both overt and relational reactive aggression were characterized by low stress management and poor emotional regulation $[32,36]$. On the other hand, the analysis of family function and aggressive behavior supports the results recently obtained by Martínez et al. [43], where the family acts as a protective factor against the aggressive behavior of adolescents.

Lastly, this study found two profiles from the predictor variables (family functioning, personal values, social values, interpersonal, and stress management) and the differences in the type of aggression. Similar studies have profiled subjects by type of aggression [47]. 


\section{Conclusions}

These findings demonstrate the relationship between the variables studied and which dimensions have to be considered for intervention or in developing a tool since not all of them predicted each type of aggression. Nevertheless, the sample size should be pointed out as one of the limitations of this study. With a larger sample, future studies could be compared to find out whether the same variables explain aggressive behavior in adolescents. With regard to family functioning, it would also be of interest to find out whether the presence of aggressive behavior is due to antecedent family function or their consequence, since, at the present time, this is not clear in the literature. Regarding this variable, another limitation is detected related to the use of the scale and its validity, which is an issue that has been occasionally discussed by other authors [52], so the data obtained in the matter must be taken warily.

Lastly, highlight the practical implications of the results obtained, especially in the design of interventions aimed at the prevention of aggressive behavior, in all its forms. To this end, the relationships identified among the study variables are considered, which is why the implementation of programs based on the training of emotional intelligence or on the acquisition of values in adolescents is considered fundamental.

Author Contributions: M.d.M.M.J., M.d.C.P.-F., and A.B.B.M. contributed to the conception and design of the review. J.J.G.L. applied the search strategy. All authors applied the selection criteria. All authors completed the assessment of bias risk. All authors analyzed and interpreted the data. M.d.M.M.J., M.d.C.P.-F., and A.B.B.M. wrote this manuscript. M.d.C.P.-F. and J.J.G.L. edited this manuscript. M.d.M.M.J. is responsible for the overall project.

Funding: This research received no external funding.

Acknowledgments: The present study was undertaken in collaboration with the Excma. Diputación Provincial de Almería.

Conflicts of Interest: The authors declare no conflict of interest.

\section{References}

1. Smith, P.K.; Kwak, K.; Toda, Y. School Bullying in Different Cultures-Eastern and Western Perspectives; Cambridge University Press: Cambridge, UK, 2016. [CrossRef]

2. Domínguez, J.; López, A.; Pino, M.; Álvarez, E. School violence: The interpersonal teacher-student dyad. Eur. J. Investig. Health Psychol. Educ. 2013, 3, 75-86. [CrossRef]

3. Zych, I.; Ortega-Ruiz, R.; Del Rey, R. Scientific research on bullying and cyberbullying: Where have we been and where are we going. Aggress. Violent Behav. 2015, 24, 188-198. [CrossRef]

4. Crespo-Ramos, S.; Romero-Abrio, A.; Martínez-Ferrer, B.; Musitu, G. Psychosocial variables and overt school violence among adolescents. Psychosoc. Interv. 2017, 26, 125-130. [CrossRef]

5. Pérez-Fuentes, M.C.; Gázquez, J.J. Variables related to violent behavior in the school according to the students. Int. J. Psychol. Psychol. Ther. 2010, 10, 427-437.

6. Cava, M.J.; Martínez, B. Adolescencia y Familia: Nuevos Retos del siglo XXI; Trillas: México, DF, Mexico, 2013.

7. Fernández-Batanero, J.M. School conviviality. A study in the province of Seville (Spain). Int. J. Educ. Resear Innov. 2015, 3, 78-93.

8. Torregrosa, M.S.; Inglés, C.J.; Estévez-López, E.; Musitu, G.; García-Fernández, J.M. Assessment of violent behaviour in adolescence: Review of questionnaires, inventories, and scales in Spanish population. Aula Abierta 2011, 39, 37-50.

9. Nieto, B.; Portela, I.; López, E.; Domínguez, V. Verbal violence in students of compulsory secondary education. Eur. J. Investig. Health Psychol. Educ. 2018, 8, 5-14. [CrossRef]

10. García-Sancho, E.; Salguero, J.M.; Vasquez, E.A.; Fernández-Berrocal, P. Validity and reliability of the Spanish version of the displaced aggression questionnaire. Psicothema 2016, 28, 96-101. [CrossRef]

11. Marsee, M.A.; Frick, P.J. Callous-unemotional traitsand aggression in youth. In Emotions, Aggression, and Morality in Children: Bridging Development and Psychopathology; Arsenio, W., Lemerise, E., Eds.; American Psychological Association: Washington, DC, USA, 2010; pp. 137-156. 
12. Vitaro, F.; Brendgen, M. Subtypes of aggressive behaviors: Etiologies, development, and consequences. In Antisocial Behavior and Crime: Contributions of Theory and Evaluation Research in Prevention and Intervention; Bliesner, T., Beelman, A., Stemmler, M., Eds.; Hogrefe: Goettingen, Germany, 2011.

13. Manring, S.; Elledge, L.C.; Swails, L.W.; Vernberg, E.M. Functions of aggression and peer victimization in elementary school children: The mediating role of social preference. J. Abnorm. Child Psychol. 2018, 46, 795-809. [CrossRef]

14. Centifanti, L.C.M.; Fanti, K.A.; Thomson, N.D.; Demetriou, V.; Anastassiou-Hadjicharalambous, X. Types of relational aggression in girls are differentiated by callous-unemotional traits, peers and parental overcontrol. Behav. Sci. 2015, 5, 518-536. [CrossRef]

15. López-Castedo, A.; Álvarez, D.; Domínguez, J.; Álvarez, E. Expressions of school violence in adolescence. Psicothema 2018, 30, 395-400. [CrossRef] [PubMed]

16. Molero, M.M.; Pérez-Fuentes, M.C.; Gázquez, J.J. Aggressive, antisocial and delinquent behaviors as a function of gender and school performance. Rev. Psicol. Educ. 2016, 11, 25-42.

17. Rieffe, C.; Broekhof, E.; Kouwenberg, M.; Faber, J.; Tsutsui, M.M.; Güroglu, B. Disentangling proactive and reactive aggression in children using self-report. Eur. J. Dev. Psychol. 2016, 13, 439-451. [CrossRef] [PubMed]

18. Van Hazebroek, B.C.M.; Olthof, T.; Goossens, F.A. Predicting aggression in adolescence: The interrelation between (a lack of) empathy and social goals. Aggress. Behav. 2017, 43, 204-214. [CrossRef] [PubMed]

19. Jara, N.; Casas, J.A.; Ortega-Ruiz, R. Proactive and reactive aggressive behavior in bullying: The role of values. Int. J. Educ. Psychol. 2017, 6, 1-24. [CrossRef]

20. Ettekal, I.; Ladd, G.W. Costs and benefits of children's physical and relational aggression trajectories on peer rejection, acceptance, and friendships: Variations by aggression subtypes, gender, and age. Dev. Psychol. 2015, 51, 1756-1770. [CrossRef] [PubMed]

21. Pérez-Fuentes, M.C.; Molero, M.M.; Carrión, J.J.; Mercader, I.; Gázquez, J.J. Sensation-Seeking and Impulsivity as Predictors of Reactive and Proactive Aggression in Adolescents. Front. Psychol. 2016, 7, 1447. [CrossRef] [PubMed]

22. Jiménez, T.I.; Estévez, E. School aggression in adolescence: Examining the role of individual, family and school variables. Int. J. Clin. Health Psychol. 2017, 17, 197-296. [CrossRef]

23. Hofmann, V.; Müller, C.M. Avoiding antisocial behavior among adolescents: The positiveinfluence of classmates' prosocial behavior. J. Adolesc. 2018, 68, 136-145. [CrossRef]

24. Molero, M.M.; Pérez-Fuentes, M.C.; Carrión, J.J.; Luque, A.; Garzón, A.; Martos, A.; Simón, M.M.; Barragán, A.B.; Gázquez, J.J. Antisocial Behavior and Interpersonal Values in High School Students. Front. Psychol. 2017, 8, 170. [CrossRef]

25. Penado, M.; Andreu, J.M.; Peña, E. Reactive, proactive and mixed type aggression: Analysis of indvidual risk factors. Anu. Psicol. Jurídica 2014, 24, 37-42. [CrossRef]

26. Frick, P.J.; Dickens, C. Current perspectives on conduct disorder. Curr. Psychiatry Rep. 2006, 8, 59-72. [CrossRef] [PubMed]

27. Grusec, J.E. Parents' Attitudes and Beliefs: Their Impact on Children's Development; Parenting Skills: New York, NY, USA, 2007.

28. Martínez, I.; García, J.F. Impact of parenting styles on adolescents' self-esteem and internalization of values in Spain. Span. J. Psychol. 2007, 10, 338-348. [CrossRef] [PubMed]

29. Martínez, I.; García, J.F. Internalization of values and self-esteem among Brazilian teenagers from authoritative, indulgent, authoritarian, and neglectful homes. Adolescence 2008, 43, 13-29. [PubMed]

30. García, O.F.; Serra, E.; Zacares, J.J.; García, F. Parenting styles and short- and long-term socialization outcomes: A study among Spanish adolescents and older adults. Psychosoc. Interv. 2018, 27, 153-161. [CrossRef]

31. Sánchez-García, M.; Lucas-Molina, B.; Fonseca-Pedrero, E.; Pérez-Albéniz, A.; Paino, M. Emotional and behavioral difficulties in adolescence: Relationship with emotional well-being, affect, and academic performance. An. Psicol. 2018, 34, 482-489. [CrossRef]

32. Zych, I.; Beltrán-Catalán, M.; Ortega-Ruiz, R.; Llorent, V.J. Social and Emotional Competencies in Adolescents Involved in Different Bullying and Cyberbullying Roles. Rev. Psicodidact. 2018, 23, 86-93. [CrossRef]

33. Steinberg, L.; Morris, A.S. Adolescent development. Annu. Rev. Psychol. 2001, 52, 52-83. [CrossRef]

34. García, O.F.; López-Fernández, O.; Serra, E. Raising Spanish children with an antisocial tendency: Do we know what the optimal parenting style is? J. Interpers. Violence 2018. [CrossRef] 
35. Inglés, C.J.; Torregrosa, M.S.; García-Fernández, J.M.; Martínez-Monteagudo, M.C.; Estévez, E.; Delgado, B. Aggressive behavior and emotional intelligence in adolescence. Eur. J. Educ. Psychol. 2014, 7, $29-41$. [CrossRef]

36. Euler, F.; Steinlin, C.; Stadler, C. Distinct profiles of reactive and proactive aggression in adolescents: Associations with cognitive and affective empathy. Child Adolesc. Psychiatry Ment. Health 2017, 11, 1-14. [CrossRef] [PubMed]

37. Steinberg, L. We know some things: Parent-adolescent relationships in retrospect and prospect. J. Res. Adolesc. 2001, 11, 1-19. [CrossRef]

38. Moratto-Vásquez, N.S.; Cárdenas-Zuluaga, N.; Berbesi-Fernández, D.Y. School Climate and Family Functionality as Associated Factors to Bullying in Students of Antioquia, Colombia. Pensam. Psicol. 2017, 15, 63-72. [CrossRef]

39. Cutrín, O.; Gómez-Fraguela, J.A.; Maneiro, L.; Sobral, J. Effects of parenting practices through deviant peers on nonviolent and violent antisocial behaviours in middle- and late-adolescence. Eur. J. Psychol. Appl. Leg. Context 2018, 9, 75-82. [CrossRef]

40. Rodríguez, A.; Revuelta, L.; Sarasa, M.; Fernández, O. The role of parental socialization styles in school engagement and academic performance. Eur. J. Educ. Psychol. 2018, 11, 123-139. [CrossRef]

41. De la Torre, M.J.; Casanova, P.F.; Carpio, M.V.; Cerezo, M.T. Perceived interparental-consistency: relationships between aggressive behavior and life satisfaction in adolescents. Eur. J. Educ. Psychol. 2013, 6, 135-149. [CrossRef]

42. Skripkauskaite, S.; Hawk, S.T.; Branje, S.J.T.; Koot, H.M.; van Lier, P.A.C.; Meeus, V. Reactive and proactive aggression: Differential links with emotion regulation difficulties, maternal criticism in adolescence. Aggress. Behav. 2015, 41, 214-226. [CrossRef] [PubMed]

43. Martínez, I.; Murgui, S.; García, O.F.; García, F. Parenting in the Digital Era: Protective and Risk Parenting Styles for Traditional Bullying and Cyberbullying Victimization. Comput. Hum. Behav. 2019, 90, 84-92. [CrossRef]

44. Castillo-Gualda, R.; Cabello, R.; Herrero, M.; Rodríguez-Carvajal, R.; Fernández-Berrocal, P. A Three-year emotional intelligence intervention to reduce adolescent aggression: The mediating role of unpleasant affectivity. J. Res. Adolesc. 2017, 28, 186-198. [CrossRef]

45. Paciello, M.; Muratori, P.; Ruglioni, L.; Milone, A.; Buonanno, C.; Capo, R.; Lochman, J.E.; Barcaccia, B. Personal values and moral disengagement promote aggressive and rule-breaking behaviours in adolescents with disruptive behaviour disorders: A pilot study. Int. J. Offender Ther. Comp. Criminol. 2017, 61, 46-63. [CrossRef]

46. Mera, R.M.; Macías, G.L.; Bravo, G.R. Family Dysfunction and Aggression Behavior among Peers: Case 8 of the Olmedo Millennium Unit. Available online: https:/ / www.eumed.net/rev/caribe/2018/04/disfuncionfamiliar.html (accessed on 6 February 2019).

47. Polman, H.; Orobio, B.; Koops, W.; van Boxtel, H.W.; Merk, W.M. A meta-analysis of the distinction between reactive and pro active aggression in children and adolescents. J. Abnorm. Child Psychol. 2007, 35, 522-535. [CrossRef] [PubMed]

48. Marsee, M.A.; Barry, C.T.; Childs, K.K.; Frick, P.J.; Kimonis, E.R.; Muñoz, L.C.; Aucoin, K.J.; Fassnacht, G.M.; Kunimatsu, M.M.; Lau, K.S. Assessing the forms and functions of aggression using self-report: Factor structure and invariance of the Peer Conflict Scale in youths. Psychol. Assess. 2011, 23, 792-804. [CrossRef] [PubMed]

49. Pérez-Fuentes, M.C.; Molero, M.M.; Martos, A.; Barragán, A.B.; Gázquez, J.J.; Sánchez-Marchán, C. Spanish analysis and validation of Peer Conflict Scale. Eur. J. Educ. Psychol. 2016, 9, 56-62. [CrossRef]

50. Bellón, J.A.; Delgado, A.; Luna, J.D.; Lardelli, P. Validity and reliability of the Apgar-family questionnaire on family function. Aten Primaria 1996, 18, 289-296.

51. Smilkstein, G.; Ashworth, C.; Montano, D. Validity and reliability of the Family APGAR as a test of family function. J. Fam. Pract. 1982, 15, 303-311. [PubMed]

52. Gardner, W.; Nutting, P.A.; Kelleher, K.J.; Werner, J.J.; Farley, T.; Stewartm, L.; Hartsell, M.; Orzano, A.J. Does the family APGAR effectively measure family functioning? J. Fam. Pract. 2001, 50, 19-25. [PubMed]

53. Bar-On, R.; Parker, J.D.A. Emotional Quotient Inventory: Youth Version (EQ-i:YV): Technical Manual; MultiHealth Systems: Toronto, ON, Canada, 2000. 
54. Pérez-Fuentes, M.C.; Gázquez, J.J.; Mercader, I.; Molero, M.M. Brief Emotional Intelligence Inventory for Senior Citizens (EQ-i-M20). Psicothema 2014, 26, 524-530. [CrossRef]

55. Antolín, L.; Oliva, A.; Pertegal, M.A.; López, A.M. Development and validation of a scale to assess positive youth development values. Psicothema 2011, 23, 153-159. 